\title{
The writing life with Vincent Lam
}

$\mathrm{D}$ r. Vincent Lam loathes distractions. When he works on a novel, he locks himself in a room and wears sound-cancelling headphones to stifle noise from his three young children. He writes on a computer detached from the Internet so email can't interrupt. And, of course, while polishing prose, he dare not even think about his most recent shift as an emergency department physician at Toronto East General Hospital.

"Often my life feels like a partially successful effort in containing complete and utter chaos," says the author of the new novel, The Headmaster's Wager. It's his first fiction since Bloodletting \& Miraculous Cures, which won the 2006 Scotiabank Giller Prize.

"I'm at the hospital; I'm writing a novel; I' $m$ changing a diaper. This is the day in the life of me. I try to be in the moment when I'm in the moment. When I'm with the kids, I fight down the urge to be thinking about my novel or listening to a medical lecture on a $\mathrm{CD}$ at the same time."

This may sound like the 37-year-old Lam has successfully learned to compartmentalize his life, that a wall separates his two occupations as physician and writer. Actually, there seems to be considerable crossover between those two passions far beyond the 2006 book, The Flu Pandemic and You: A Canadian Guide, co-written with Colin Lee. Lam has also written a short commissioned biography of Tommy Douglas, the father of medicare (see CMAJ 2012; 184:329).

First of all, Lam thinks that being a physician makes him a better writer. Working in an emergency department, doctors are faced with every possible emotion and drama. This can be helpful to a writer trying to construct credible fiction, to make characters talk, act and feel like real people.

"It gives one a feel for dialogue and for how conflicts play out and tricks people play in their own minds," says Lam. "These things are all very important for a writer."
Second, Lam says that being a writer helps him to be a better physician. Both writers and physicians, he says, must have "a nose for narrative." Honing those narrative skills while writing fiction can help a doctor better understand a patient's "narrative" - the combined physical, psychological and environmental issues that ultimately led the patient to seek medical help.

"I view my work as a doctor as very much a form of work in which I engage with narrative and the people who come in are part of a story. The things they tell me about what they are experiencing are elements of a story. So, it's a big part of my job, in addition to understanding the science of medicine, to see where they are at in the story and to try to help them manage the story and to try to tell the story using medical knowledge. Because I work as a writer, I probably recognize that more explicitly than I might otherwise."

To complete the patient's narrative, the doctor must be a good listener and know when to interrupt with questions.

"You have to have your antennae up for what sometimes is an important gap in the story."

Lam was born in London, Ont. and raised in Ottawa. His parents were originally part of the ethnic Chinese population of Vietnam that is the focus of The Headmaster's Wager. Indeed, the main character in the novel was inspired by Lam's own gambling, womanizing grandfather whom we first met in one of the stories of Bloodletting.

The novel unfurls in the years leading to the communist takeover and is peopled by brutal villains, scheming women and monstrous duplicity. The libidinous headmaster makes deals with the devil to become rich, to save his son's life, to fall in love and to save his own skin. Although not a conventional hero, the headmaster eventually manages to earn our sympathy as calamities unfold. The ending invites a sequel. Lam does not disagree.

As a child, Lam initially wanted to be a writer. Many a wannabe author

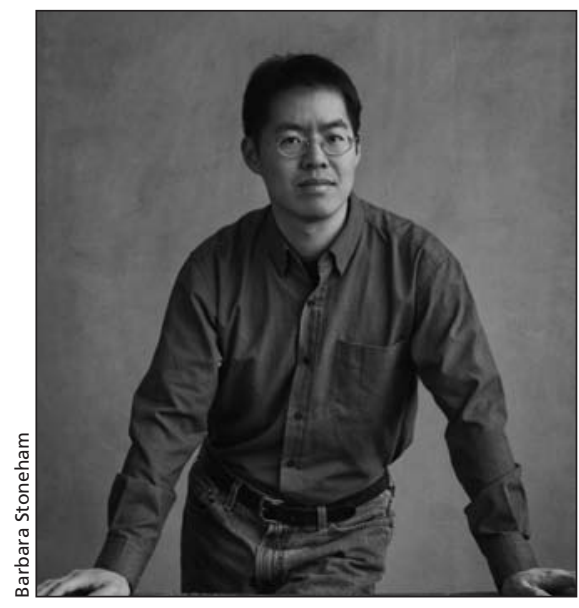

has financed that obsession with a day job as a bartender or sales clerk. Lam chose medicine.

"I will happily admit I was probably drawn to medicine for an imperfect set of reasons. I thought it would be a great profession in order to have that window into human processes in order to be a better writer. This was part of it. And part of it was also because I thought it would be also great just to be able to eat and pay rent on a consistent basis."

But Lam fell in love with medicine after becoming a doctor and, despite finding success as a writer, wants to continue being a physician.

"I became very enamoured with all the other important things in medicine and some of those important things are, to me, the importance of narrative and then, of course, a huge area of importance is the act of trying to help people in the narrative in their life. I need to say all of that because since I fell in love with medicine for what I think are the right reasons, I now find it quite hard to stop doing medicine."

So, Lam continues to pursue two careers and two sets of narratives. The result is "complete and utter chaos" dulled occasionally by soundcancelling headphones.

Paul Gessell

Journalist

Ottawa, Ont.

CMAJ 2012. DOI:10.1503/cmaj.120799 